\title{
ÍNDIO: UMA VISÃO CIENTÍFICA E TECNOLÓGICA DE UM METAL ESTRATÉGICO
}

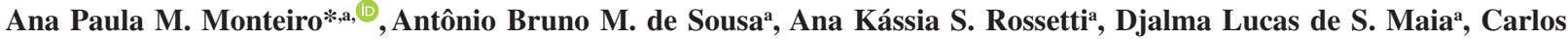 \\ Henrique Z. Martins a e Oswaldo L. Alves ${ }^{\#, a}$ \\ aDepartamento de Química Inorgânica, Instituto de Química, Universidade Estadual de Campinas, 13083-970 Campinas - SP, Brasil
}

Recebido em 17/07/2019; aceito em 08/10/2019; publicado na web em 21/11/2019

\begin{abstract}
INDIUM: A SCIENTIFIC AND TECHNOLOGICAL VIEW OF A STRATEGIC METAL. Indium have been widely investigated by scientists because of its several interesting properties and its use in different applications in the manufacture of TVs screens, computers, cell phones, solar panels, electroluminescent diodes (LEDs), organic electroluminescent diodes (OLEDs), DNA and antibody sensors, electrocatalysts, architectural glass coatings, low melting alloys, thermal interface materials, aircraft engine bearings, among others. The economic urge to make devices more cost effective and efficient has guide developments in different deposition technologies, such as dip-coating, plating, thick and thin film deposition. However, indium is classified as a critical metal. In this sense, we discussed the economic viability and spatial distribution of the indium resources in Brazil and worldwide considering that its supply still remains a concern. On top of that, the present review discusses the scientific and technological aspects of indium materials and highlights the major advances regarding their synthesis, properties and applications.
\end{abstract}

Keywords: indium and chemical element; properties; applications; perspectives; semimetal element.

\section{INTRODUÇÃO}

O índio foi descoberto em 1863 por Ferdinand Reich e Hieronymus Theodor Richter nos laboratórios da Academia de Minas de Freiberg na Alemanha. ${ }^{1,2} \mathrm{Na}$ realização de estudos envolvendo o elemento tálio foi observada uma linha de emissão atômica, até então desconhecida. Os autores concluiram que tratava-se de um novo elemento, ao qual deram o nome índio, em função do aparecimento de uma emissão de cor azul índigo que foi atribuída como sua característica. Reich e Richter isolaram uma amostra inédita do índio e fizeram a primeira apresentação pública deste feito na Exposição Mundial de Paris em 1867. ${ }^{1}$

O índio geralmente é encontrado associado a outros elementos, sendo o mais comum o zinco, com o qual forma o minério denominado esfarelita, cujas as principais reservas mundiais encontram-se na China. ${ }^{2,3}$ Após sua descoberta em 1863, começou a ser utilizado amplamente um século depois, especialmente em materiais semicondutores e dispositivos de cristal líquido (LCD, Liquid Crystal Devices). Nos últimos 30 anos, a demanda pelo elemento índio foi impulsionada pela sua aplicação em tecnologias inovadoras, atraindo a atenção da academia, indústria e governo. As suas propriedades ${ }^{1,2}$ de ductilidade, maleabilidade, semicondutividade e transparência permitem sua utilização industrial na fabricação de telas de TVs, computadores, celulares, painéis solares, lâmpadas eletroluminescentes (LED), revestimentos de vidros, ligas de baixo ponto de fusão, materiais térmicos interfaciais, rolamentos de motores, entre outros. ${ }^{3-6}$

O índio está entre as vinte matérias-primas críticas em importância econômica sobretudo devido aos aspectos ligados a sua oferta mundial. Somadas a isso, é necessário considerar a questão relacionada à forte intensificação da demanda pelo setor produtivo e à falta de informações precisas sobre as reservas de minérios de índio já identificadas. ${ }^{3}$ Neste contexto, este trabalho propõe não só divulgar a importância do elemento índio, como também destacar o impacto científico, tecnológico e econômico no Brasil e no mundo.

\footnotetext{
*e-mail: apdemm@gmail.com

"e-mail alternativo: oalves@iqm.unicamp.br
}

\section{PROPRIEDADES GERAIS}

O índio possui a configuração eletrônica $[\mathrm{Kr}] 4 \mathrm{~d}^{10} 5 \mathrm{~s}^{2} 5 \mathrm{p}^{1} \mathrm{e}$ apresenta estados de oxidação mono, di e trivalentes, formando compostos tais como os exemplos que se seguem InCl, $\mathrm{In}_{2} \mathrm{~S}$, InO, $\mathrm{InCl}_{2}, \mathrm{In}_{2} \mathrm{O}_{3}$ e InN. ${ }^{1,2}$

$\mathrm{O}$ índio apresenta diferentes graus de solubilidade em função do $\mathrm{pH}$ e da temperatura. Na forma metálica é insolúvel tanto em água quanto em meio alcalino e solúvel à temperatura ambiente em ácidos diluídos, sendo que o processo de solubilização é dependente da temperatura e da concentração do ácido. Por exemplo, em ácido sulfúrico concentrado a frio, ocorre a dissolução com a concomitante liberação de hidrogênio e formação do sulfato de índio anidro. Por outro lado, no processo a quente, ocorre a liberação do dióxido de enxofre e no caso do ácido nítrico a quente ocorre a formação de óxidos de nitrogênio. ${ }^{4} \mathrm{Em}$ ácido clorídrico concentrado o metal é dissolvido com liberação de hidrogênio.

As propriedades relacionadas aos possíveis estados de oxidação do índio, tais como a afinidade eletrônica e o potencial padrão de redução são negativas levando a formação de cátions. Os compostos de In (III) são mais estáveis e, consequentemente, mais comuns. Em soluções aquosas observa-se que a estabilidade química decresce na seguinte ordem: In (III) $>$ In (I) $>$ In (II) ${ }^{4}$

O índio forma compostos estáveis com halogênios, oxigênio, enxofre e fósforo, dentre estes destacam-se os sulfetos, cloretos, hidróxidos e óxidos. Também são formados compostos estáveis com elementos do grupo 15, como InAs, InSb e InP. Na presença de halogênios e ácidos orgânicos em meio aquoso o índio forma complexos de coordenação bem estabelecidos. Os halogenetos de índio formam com ligantes neutros (L) uma grande variedade de complexos do tipo $\operatorname{InX}_{3} \mathrm{~L}_{3} \cdot{ }^{1,2,4}$

Referente às suas propriedades físicas, o índio se apresenta como um sólido metálico de alta maleabilidade, ductilidade e plasticidade. ${ }^{2,3} \mathrm{O}$ índio metálico e ligas com alto teor de índio têm como características a capacidade de autoadesão e soldagem a frio, permitindo que materiais revestidos com este elemento possam ser unidos instantaneamente.

Ao ser utilizado como revestimento de superfícies de vidros, micas, quartzos, cerâmicas vítreas e certos óxidos metálicos por 
fricção, apresenta a propriedade de molhabilidade. É um material ideal para ser usado como vedação em equipamentos criogênicos e/ou a vácuo, pois sua flexibilidade e maleabilidade permanecem inalteradas até temperaturas próximas do zero absoluto. Quando adicionado em quantidades relativamente pequenas a sistemas metálicos puros ou ligas, pode aumentar a resistência e dureza dos materiais compósitos resultantes. Em soldas utilizadas na indústria eletrônica, onde a alta pureza é fundamental, as ligas de índio podem reduzir a temperatura de fusão da solda, ${ }^{2,4}$ evitando a deteriorização dos componentes eletrônicos.

As principais propriedades fisico-químicas do índio são apresentadas na Tabela 1. É possível verificar que o índio apresenta baixo ponto de fusão, quando comparado a outros metais, alto ponto de ebulição e alto coeficiente de expansão térmica linear, baixa dureza e baixa eletronegatividade de Pauli. O metal apresenta uma suscetibilidade magnética negativa, que permite classificá-lo como sendo um material diamagnético. Vale ainda destacar sua baixa resistividade elétrica em comparação com os outros metais, característica comum dos elementos do grupo 13 da Tabela Periódica. ${ }^{1,4}$

São conhecidos cerca de 73 isótopos do índio, sendo todos radioativos e de baixos tempos de meia-vida, com exceção dos isótopos ${ }^{113}$ In e ${ }^{115} \mathrm{In}$, que são considerados estáveis, representando, respectivamente, $4,3 \%$ e $95,7 \%$ da quantidade total de índio encontrado na crosta terrestre. ${ }^{1,4}$

A toxicidade do índio varia dependendo do material e da forma que é administrado, bem como, sua concentração e tempo de exposição. O índio na forma metálica ou em compostos são considerados tóxicos quando ingeridos ou inalados na forma de pequenas partículas e/ou vapores. ${ }^{6}$ A exposição crônica durante o seu processo de produção pode ocasionar a perda dos dentes, dores nas articulações, desordens do sistema nervoso e gastrointestinal, problemas cardíacos e debilidade geral. A dose letal de injeção subcutânea ou intramuscular de índio em sua forma iônica em camundongos é de 0,15 $60,00 \mathrm{mg} \mathrm{kg}^{-1} .{ }^{4}$ Não obstante, alguns autores consideram que o índio metálico e seus compostos possuem baixa ou nenhuma toxicidade.

\section{OCORRÊNCIA E PRODUÇÃO MUNDIAL}

O índio é o $64^{\circ}$ elemento mais abundante da Terra, ocorrendo em concentrações de 0,25 e 0,02 ppm na crosta continental e nos oceanos, respectivamente. ${ }^{1}$ Pode ser obtido industrialmente via o tratamento de resíduos de minérios de zinco e chumbo e isolado através da formação de seu sal seguido de eletrólise em meio aquoso. .,2,5 $^{-1}$

O índio está associado, em pequenas quantidades, em muitos minerais. ${ }^{5}$ Os minérios mais comuns onde ocorre são a esfarelita $(\mathrm{ZnS})$ e a galena $(\mathrm{PbS})$, com teores da ordem de $0,05 \%$. Acima deste valor, o minério já é considerado rico em índio. São descritas a ocorrência de minérios com maiores concentrações, contudo são extremamente raros, como a indita $\left(\mathrm{FeIn}_{2} \mathrm{~S}_{4}\right)$, encontrada na Sibéria. Minérios com altas concentrações de índio $(0,1$ a $1,0 \%)$ são encontrados principalmente na Bolívia, Inglaterra (Cornwall) e Canadá (Brunswick) e, em concentrações menores, na Rússia, Europa, Peru, Canadá, Oeste dos EUA e China. ${ }^{1,5,6}$ A Figura 1 mostra um mapa global com a localização da maioria dos depósitos de índio organizados considerando as seguintes situações: depósitos de índio relatado e quantificado, relatado mas não quantificado (inferido), e índio associado a minérios de $\mathrm{Pb}-\mathrm{Zn}$ e $\mathrm{Cu} .{ }^{3}$ Caso estes recursos forem inteiramente transformados em reservas e produção, serão suficientes para atender o crescimento contínuo do consumo no próximo século, particularmente graças aos volumes significativos dos depósitos inferidos proveniente dos minérios de $\mathrm{Pb}-\mathrm{Zn}$.

Os métodos de extração do índio variam dependendo da natureza

Tabela 1. Principais propriedades fisico-químicas do índio metálico ${ }^{1,4}$

\begin{tabular}{|c|c|c|c|}
\hline Número atômico & 49 & Entalpia de fusão $\left(\mathrm{kJ} \mathrm{mol}^{-1}\right)$ & 3,28 \\
\hline Massa molar $\left(\mathrm{g} \mathrm{mol}^{-1}\right)$ & 114,818 & Entalpia de vaporização $\left(\mathrm{kJ} . \mathrm{mol}^{-1}\right)$ & 232 \\
\hline Ponto de fusão $\left({ }^{\circ} \mathrm{C}\right)$ & 156,6 & Entropia padrão a $25^{\circ} \mathrm{C}\left(\mathrm{J} \mathrm{K}^{-1} \mathrm{~mol}^{-1}\right)$ & 57,82 \\
\hline Ponto de ebulição $\left({ }^{\circ} \mathrm{C}\right)$ & 2080 & $\begin{array}{l}\text { Energia padrão de Gibbs de formação do } \operatorname{In}_{2} \mathrm{O}_{3} \text { a } \\
25^{\circ} \mathrm{C}\left(\mathrm{kJ} \mathrm{mol}^{-1}\left(1 \mathrm{O}_{2}\right)\right)\end{array}$ & -554 \\
\hline Densidade a $20^{\circ} \mathrm{C}\left(\mathrm{g} \mathrm{cm}^{-3}\right)$ & 7,31 & Resistividade elétrica ( $\mu$ ohm.cm) & 8,37 \\
\hline Dureza (Mohs) & 1,2 & Suscetibilidade magnética a $25^{\circ} \mathrm{C}\left(\mathrm{m}^{3} \mathrm{~kg}^{-1}\right)$ & $-7,0 \times 10^{-9}$ \\
\hline Eletronegatividade de Pauli & 1,78 & Coeficiente de expansão linear a $25^{\circ} \mathrm{C}\left(\mathrm{K}^{-1}\right)$ & $32,1 \times 10^{-6}$ \\
\hline
\end{tabular}

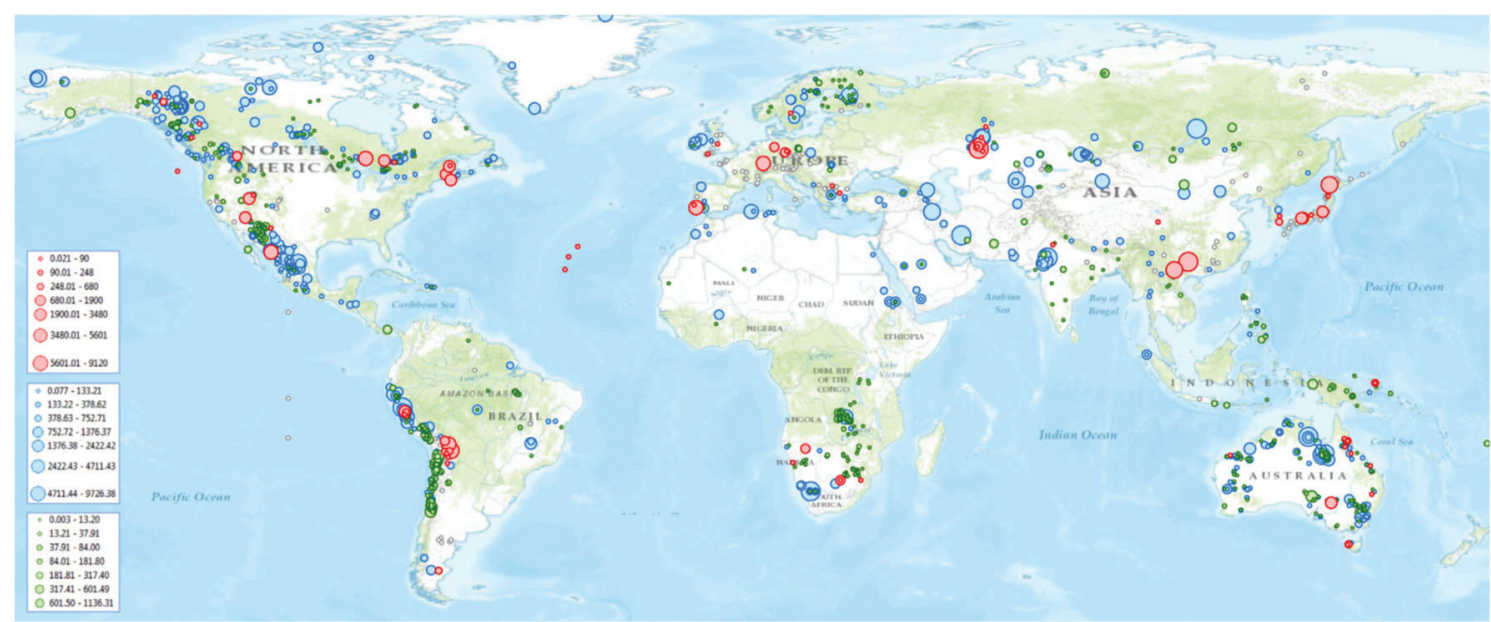

Figura 1. Mapa global de depósitos de índio relatado e quantificado (vermelho, $N=101$ ), relatado mas não quantificado (branco, $N=219)$ e inferido em $\mathrm{Pb}$-Zn (azul, $N=591)$ e em $\mathrm{Cu}$ (verde, $N=576)$. Quantidades descritas na legenda estão em toneladas. Adaptado da Ref. 3 
do minério ou resíduo empregado. Os resíduos podem ser do refino dos minérios de zinco, da recuperação de cádmio, de rejeitos de soluções de sulfato de zinco ou da escória de fornos da fundição de chumbo. A purificação final e recuperação na forma de metal são realizadas geralmente por métodos eletrolíticos. ${ }^{5}$ Além disso, com a crescente utilização de placas LCD aumentou a preocupação com a destinação desse lixo eletrônico, que contém índio, e a diminuição do custo das matérias-primas. ${ }^{3,6}$ Recentemente, rotas de reciclagem foram desenvolvidas em todo o mundo, a fim de resolver questões de demanda e fornecimento de índio. Um caminho para produção secundária/metalurgia do índio é a reciclagem do óxido de índio-estanho (ITO) após sua fase de pulverização. Outra opção para produção secundária/metalurgia é a reciclagem de resíduos relacionados com materiais elétricos e eletrônicos. Atualmente, a reciclagem é responsável por cerca de $60 \%$ da produção mundial de índio, na qual a principal fonte é o óxido de índio-estanho (ITO) presente nas telas de cristal líquido. Os principais países recicladores mundiais de índio são a China, Japão e Coréia, onde a maior parte dos filmes finos de ITO são produzidos. ${ }^{3,6}$ Com este tipo de operação, ou seja, o aumento da eficiencia da produção e a reciclagem, está se construindo um equilíbrio entre a demanda e o fornecimento do metal.

\section{IMPACTOS NA CIÊNCIA E TECNOLOGIA E ASPECTOS ECONÔMICOS GLOBAIS}

Esta seção destaca o papel da pesquisa científica sobre o índio (In) como uma força motriz para seu posicionamento como um metal crítico altamente estratégico no cenário tecnológico e econômico global. Devido a seu caráter integrador e multidisciplinar, bem como elevado potencial de inovação associado, a pesquisa envolvendo o elemento índio tem permitido a implementação de tecnologias verdes em indústrias dos setores de energia renovável (painéis solares e turbinas eólicas) e produtos eletrônicos amplamente utilizados pela sociedade (telas de cristal líquido presentes em computadores e dispositivos móveis). ${ }^{3,7,8}$

A Figura 2 mostra a evolução mundial do número de publicações científicas envolvendo o elemento índio em revistas indexadas ao longo dos anos. O gráfico foi elaborado utilizando a base de dados Scopus através da combinação de palavras-chave e operadores conjuntos (Indium AND chemical element), sendo totalizados 1417 resultados. ${ }^{9}$

É possível verificar um crescimento significativo no número de publicações em meados da década de oitenta. Este fato corrobora com o aumento de dez vezes na produção mundial do In a partir dos anos noventa e com a intensificação da demanda pelo mercado consumidor de "commodities" contendo o metal. ${ }^{9}$ Vale ressaltar que a pesquisa relacionada ao In abrange diferentes áreas do conhecimento sendo impulsionada pela inter e multidisciplinaridade. A Figura 3 mostra que $81 \%$ da pesquisa mundial sobre o In está associada a quatro grandes áreas (Química, Ciência dos Materiais, Engenharias e Física-Astronomia).

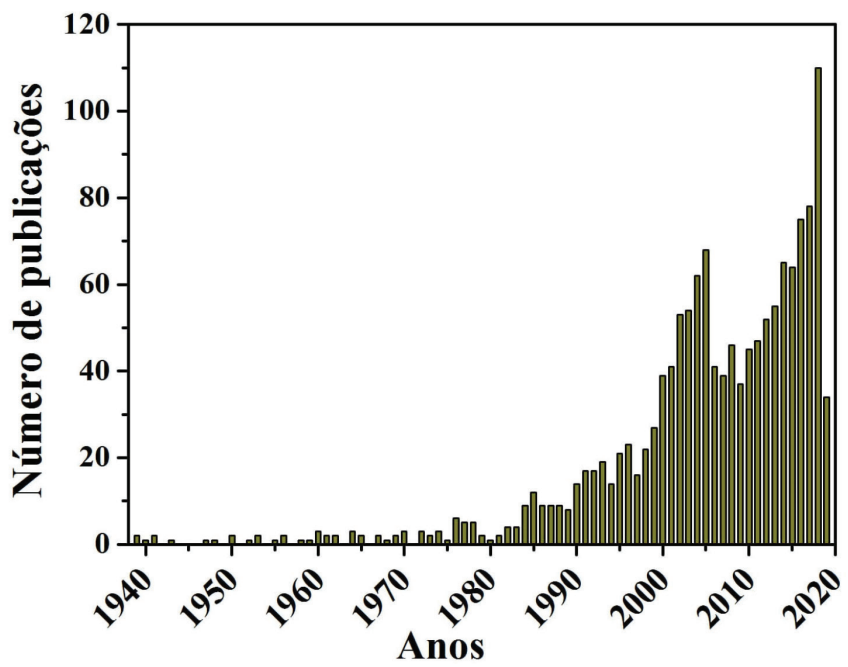

Figura 2. Evolução mundial do número de publicações científicas sobre o Índio ao longo dos anos até 2019

Um recorte mais fino nestas quatro grandes áreas nos levam para quatro maiores aplicações do índio: (i) filmes finos de óxido de índio-estanho (ITO), (ii) semicondutores, (iii) ligas e soldas e (iv) compostos químicos. Esse recorte das aplicações é realizado por grau de importância econômica e por isso, o ITO que é um semicondutor, é apresentado separadamente dos outros semicondutores. A Figura 4 mostra que $89 \%$ do uso do índio na indústria é empregado na obtenção de filmes finos ITO, enquanto que na pesquisa acadêmica este valor está em $17 \%$. Atualmente, as pesquisas acadêmicas têm se concentrado no desenvolvimento de novos materiais semicondutores para painéis solares, em ligas e soldas de baixo ponto de fusão, além de compostos orgânicos fotoluminescentes (OLEDs). Isso possivelmente revela uma tendência de mercado que visa intensificar as pesquisas em materiais semicondutores, especialmente em células fotovoltaicas e células solares, alinhando-se a uma tendência de investimentos

\section{Área do conhecimento}

$\%$

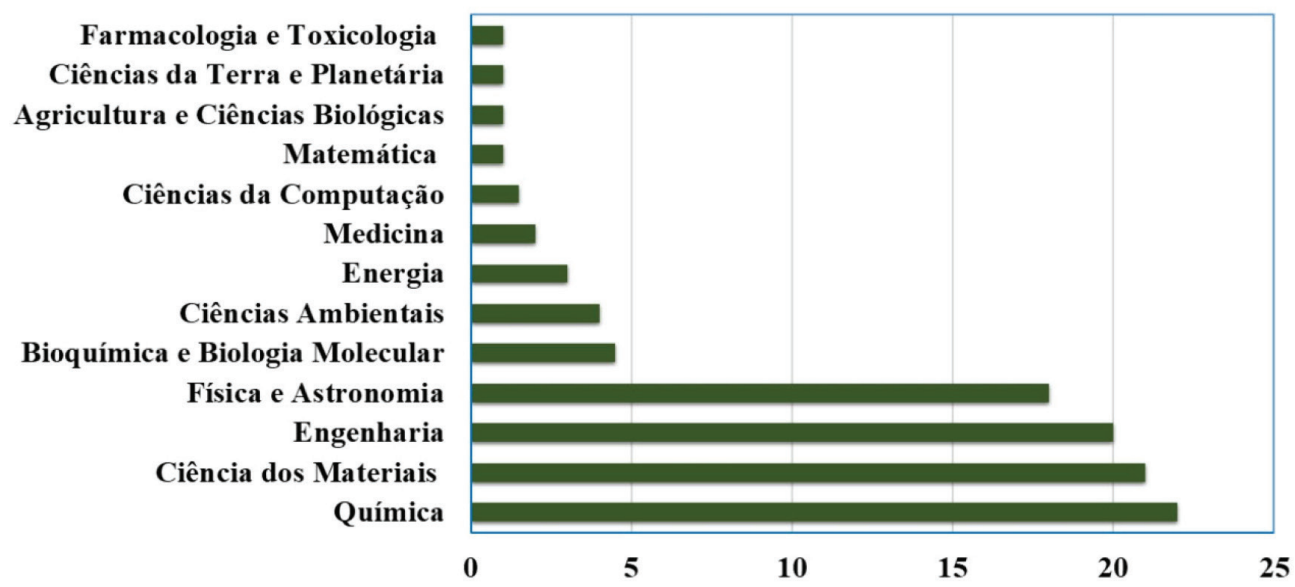

Figura 3. Divisão por áreas do conhecimento (\%) da pesquisa relacionada ao Índio. A análise foi efetuada a partir dos 1417 artigos científicos encontrados na base de dados Scopus 
para as próximas décadas, tanto dos programas de governos como das indústrias.
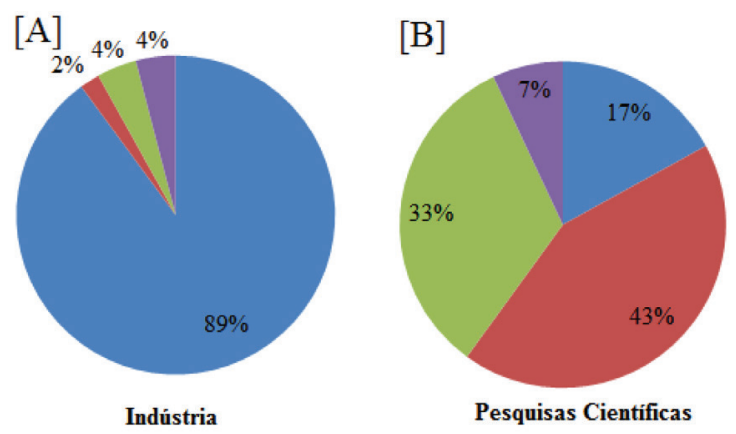

-Filmes finos ITO $\quad$ Semicondutores

Soldas e Ligas $\square$ Compostos Químicos

Figura 4- Correlação entre aplicação industrial e a pesquisa científica dos compostos de índio. [A]-Adaptado da Ref. 9 e [B]-A pesquisa foi realizada refinando os dados obtidos anteriormente com as seguintes palavras-chave ITO (226), semiconductor (611), alloy AND solder (470) e compounds (110)

O presente contexto demonstra de forma positiva que o conhecimento científico e tecnológico gerado sobre o In em universidades e centros de pesquisa no mundo está sendo transferido e incorporado pelo setor produtivo. Nesse caso, fica muito claro que ciência e indústria estão intrinsicamente ligadas na direção do desenvolvimento de produtos inovadores.

É importante reiterar que o In é um dos elementos químicos menos abundantes na Terra e que apresenta importantes gargalos na cadeia de abastecimento devido à ausência de estimativas confiáveis de fontes potencialmente exploráveis. ${ }^{10}$ Acrescente-se a isso o fato de seu fornecimento mundial ser dominado por poucos países, alguns dos quais convivendo com sérias crises políticas. Esses aspectos fazem que o In seja classificado como um metal crítico, ${ }^{3}$ a ponto de impactar diretamente a viabilidade econômica de sua exploração e seu fornecimento global de modo sustentável.

O consumo atual do In no mundo (extraído principalmente como subproduto da metalurgia do zinco) é da ordem de 800 t/ano podendo alcançar cerca de 4000 t/ano caso seja mantida a tendência de crescimento observada nas últimas duas décadas. ${ }^{6}$ Recentemente, uma avaliação global do In contabilizando 1512 depósitos minerais e empregando uma abordagem de trabalho rigorosa, demonstrou que a quantidade de In presente e estimada nestes depósitos é da ordem de $356 \mathrm{kt}$, quantidade esta suficiente para atender a demanda mundial no próximo século. ${ }^{3}$

O valor do quilo do In tem variado na faixa de US\$300 a US\$ 800 na última década. Essa flutuação está relacionada ao domínio da China sobre o mercado e, consequentemente, sua capacidade de impor restrições à exportação. ${ }^{11} \mathrm{~A}$ quantidade de recursos minerais não é um fator limitante para que o In seja economicamente extraído e comercializado e continue a agregar valor em várias tecnologias e produtos no mercado.

O potencial econômico do In fica evidenciado quando consideramos o exemplo da tecnologia do óxido de indio-estanho (ITO), um óxido condutor transparente, amplamente utilizado em telas LCD, células fotovoltaicas e biossensores. De acordo com um relatório da empresa de análise de mercado NanoMarkets, o mercado global de condutores transparentes gerará US\$ 4,6 bilhões em 2019. ${ }^{12}$ Por outro lado, para que seja realizada uma gestão sustentável desse elemento estratégico por órgãos governamentais, indústria e sociedade, quatro aspectos fundamentais devem ser considerados: i) o conhecimento aprofundado das fontes de In em depósitos de minérios no mundo; ii) o domínio científico e tecnológico para potencializar sua exploração e aplicação; iii) a tradução dessa cadeia produtiva em termos econômicos e iv) a realização de estudos relativos à natureza e adaptabilidade deste mercado.

\section{APLICAÇÕES}

O índio é utilizado de diferentes formas como óxidos, complexos, compostos binários, ternários e quartenários. Atualmente, as maiores e mais importantes aplicações do índio são: eletrodos transparentes para telas de cristal líquido de óxido de índio-estanho (ITO), ligas de baixo ponto de fusão de índio e gálio (GaIn), semicondutores em lâmpadas eletroluminescentes (LEDs) de nitreto de índio-gálio (GaInN) e células solares de seleneto de cobre-índio-gálio (CoInGaSe).

\section{Filmes Finos ITO}

O primeiro relato de síntese do filme fino de ITO foi uma patente em 1947. ${ }^{13}$ Posteriormente em 1951 e 1955, foram relatadas as primeiras sínteses empregando spray pirólise e sputtering, respectivamente. ${ }^{13}$ $\mathrm{O}$ óxido de índio $\left(\operatorname{In}_{2} \mathrm{O}_{3}\right)$ estequiométrico, sem dopagem por estanho, exibe um comportamento isolante. No entanto, quando preparado com deficiência de oxigênio pode alcançar um alto nível de dopagem tipo $n$, devido aos defeitos intrínsecos como vacâncias de oxigênio. Quando o óxido de índio é dopado com estanho denominado ITO, este atua como uma impureza doadora, por se tratar de uma espécie tetravalente (estanho) dopando uma espécie trivalente (índio). Por conseguinte, dois mecanismos de geração de elétrons condutores são possíveis nos filmes de ITO. O primeiro se dá através dos buracos de oxigênio na estrutura do óxido de índio, que fornece no máximo 2 elétrons livres, formando uma estrutura tipo $\operatorname{In}_{2} \mathrm{O}_{3-\mathrm{X}}$. O segundo acontece por meio de substituição aleatória de íons $\mathrm{In}^{3+}$ por íons $\mathrm{Sn}^{4+}$ provendo um elétron na camada de condução, formando estrutura do tipo $\operatorname{In}_{2-\mathrm{x}} \mathrm{Sn}_{\mathrm{x}} \mathrm{O}_{3}$, originando, assim, estruturas não estequiométricas, o que permite que o filme seja um bom condutor. ${ }^{13}$

$\mathrm{O}$ óxido de índio-estanho $\left(\mathrm{In}_{2} \mathrm{O}_{3}: \mathrm{Sn}\right)$, possui comumente uma relação de 9:1 em peso, podendo ser obtido na forma cristalina ou amorfa. Este material apresenta alta transmitância na região do visível, alta refletância na região do infravermelho (IR), alta condutividade e, ainda, uma grande variação no band gap $(3,3-4,3 \mathrm{eV}) .{ }^{13-15}$ Tais propriedades fazem do ITO, um material notável para uma variedade de aplicações, como células solares, ${ }^{16}$ células de cristal líquido (LCD), ${ }^{17}$ diodos emissivos luminosos orgânicos (OLEDs), ${ }^{18}$ vidros arquitetônicos, ${ }^{19}$ sensores de gás, ${ }^{20}$ biossensores, ${ }^{21}$ telas planas ${ }^{22}$ e conversores fotocatalíticos. ${ }^{23}$ No entanto, possui algumas desvantagens, dentre elas, o alto custo e a instabilidade. O filme amorfo de ITO depositado a baixas temperaturas tem alta resistência sob calor úmido, o que leva a uma diminuição em sua condutividade e transmitância de luz. ${ }^{24}$ Para minimizar essas e outras limitações e ampliar suas aplicações tecnológicas, pesquisas estão sendo realizadas no desenvolvimento de sínteses que gerem novas morfologias tais como, nanotubos, nanofitas, nanofios e nanopartículas. Dessa maneira, as propriedades dos materiais não dependem apenas de sua composição, mas também do seu tamanho e forma, os quais são influenciados pelo método de síntese. A literatura reporta inúmeros trabalhos mostrando a influência dos métodos de síntese nas propriedades deste material. ${ }^{13,24-28}$

Muitas metodologias são comumente empregadas na síntese/ fabricação dos filmes finos do ITO. Dentre elas podemos destacar: magnetron sputtering, sputtering por feixe de íons, evaporação por feixe de elétrons, deposição de vapor químico (CVD, Chemical Vapor Deposition), deposição por spray de vapor químico (SCVD, Spray Chemical Vapor Deposition) e deposição a partir de solução química que usa dip ou spin-coating. ${ }^{13,24} \mathrm{Na}$ Tabela 2 são apresentados alguns tipos de materiais, métodos de síntese, propriedades e aplicações dos 
filmes de ITO. Essas tecnologias (comerciais ou não) buscam aumentar a eficiência dos dispositivos que serão utilizados em bens finais como TVs, laptops, celulares, relógios, painéis solares, painéis luminosos, máquinas eletrônicas de vendas, caixas eletrônicos de bancos, janelas inteligentes, para-brisa de carros e aeronaves, detectores de gases, sensores de anticorpos e DNA, eletrocatalisadores, entre outros.

LCDs, OLEDs, Telas Sensíveis ao Toque, Células Solares e Janelas Arquitetônicas

O interesse em ITO aumentou consideravelmente quando este foi introduzido em telas de cristais líquidos (LCDs), substituindo gradualmente os aparelhos com tubos de raios catódicos (CTR). Hoje representa cerca de $80 \%$ do mercado mundial, pois a célula de cristal líquido é usada, além da fabricação de telas de televisão, em relógios, celulares, tablets, laptops, entre outros. A massa de índio por dispositivo é, em média, $39 \mathrm{mg}$ para um laptop, $79 \mathrm{mg}$ para um monitor de computador, $254 \mathrm{mg}$ para uma TV LCD. ${ }^{9} \mathrm{Na}$ Figura 5 são apresentados esquemas dos principais dispositivos que utilizam ITO em sua composição. Na Figura 5 [A] é mostrada uma célula de cristal líquido, a qual consiste em uma camada de cristal líquido, que se encontra entre duas camadas de substrato transparente revestido com ITO e duas camadas polarizadoras nas extremidades. ${ }^{42}$ A Figura 5 [B] apresenta uma tela sensível ao toque (touch screen) resistiva, que consiste em duas camadas condutoras transparente de ITO separadas por uma camada de spacer dots, a qual impede as camadas condutoras de se encostarem quando não há pressão na tela. Geralmente, esse substrato é flexível e quando o painel é pressionado, as duas camadas de ITO se conectam criando um contato elétrico, que é registrado como um evento por um controlador. ${ }^{42}$ A Figura 5 [C] é uma típica célula solar orgânica. Os fótons provenientes da radiação solar atravessam a camada de vidro, a camada de ITO e a camada de transporte de lacunas (PEDOT:PSS), sendo absorvidos na camada ativa (P3HT/PCBM), que produzem éxcitons, pares de elétron-buraco. A assimetria nas funções trabalho do ânodo (ITO) e cátodo (LiF/ $\mathrm{Al})$ cria um campo elétrico interno, de forma que os buracos se movimentem em direção ao ânodo e os elétrons se movimentem em direção ao cátodo. Quando os eletrodos (cátodo e ânodo) são conectados externamente, uma corrente elétrica é gerada. ${ }^{42}$ A Figura 5 [D] representa um diodo emissivo de luz orgânico (OLED), que consiste em uma camada orgânica eletroluminescente (camada emissiva $\mathrm{Alq}_{3}$ ) que se encontra entre dois eletrodos de função trabalho diferentes, normalmente um ânodo transparente (ITO) e um cátodo metálico (Al). Quando aplicada uma tensão elétrica nos eletrodos, os elétrons-buracos são injetados na camada eletroluminescente $\mathrm{Alq}_{3}$ e estes (elétrons-buracos) são recombinados gerando éxcitons, que emitem luz na região do visível. A cor da luz emitida depende do material eletroluminescente utilizado no dispositivo. Além disso, camadas de compostos orgânicos podem ser adicionadas em diferentes funções, como camada de transporte de portadores (NPB). ${ }^{42,43}$

Tabela 2. Aplicações, características e metodologias de síntese dos filmes finos de ITO

\begin{tabular}{|c|c|c|c|c|}
\hline Material & Síntese & Propriedades & Aplicação & Ref. \\
\hline $\begin{array}{l}\text { Filme de ITO em substrato } \\
\text { de vidro }\end{array}$ & $S C V D$ & $\begin{array}{l}\text { Espessura do filme: } 120 \mathrm{~nm} \\
\text { Função de trabalho: } 4,7 \mathrm{~V} \\
\text { Resistividade: } 3,7 \times 10^{-4} \Omega . \mathrm{cm} \\
\text { Luminescência: } 6500 \mathrm{~cd} / \mathrm{m}^{2}\end{array}$ & OLED & 29 \\
\hline $\begin{array}{l}\text { Filme de ITO em substrato } \\
\text { de vidro }\end{array}$ & $C V D$ & $\begin{array}{l}\text { Espessura do filme: } 200 \mathrm{~nm} \\
\text { Resistividade: } 1 \times 10^{-4} \text { W.cm } \\
\text { Sensibilidade: } 53 \mathrm{mV} / \mathrm{pH}\end{array}$ & Sensor de $\mathrm{pH}$ & 30 \\
\hline $\begin{array}{l}\text { Filme de ITO em substrato } \\
\text { de PET }\end{array}$ & RF Sputtering & $\begin{array}{l}\text { Resistência da folha: } 100 \Omega / \Upsilon \\
\text { Sensibilidade: } 54 \mathrm{mV} / \mathrm{pH}\end{array}$ & Sensor de $\mathrm{pH}$ & 31 \\
\hline ITO/Grafeno/ $\mathrm{C}_{60}: \mathrm{ZnPc}$ & $C V D$ & $\begin{array}{l}\text { Espessura do filme: } 190 \mathrm{~nm} \\
\text { Função de trabalho: } 5,2 \mathrm{~V}\end{array}$ & Dispositivos Fotovoltaicos & 32 \\
\hline $\begin{array}{l}\text { ITO/TiO } / \text { /EPM/anti-PSA/BSA/ } \\
\text { PSA }\end{array}$ & Drop-casting & Fotocorrente: $42,86 \mu \mathrm{A}$ & Biossensor Fotoeletroquímico & 33 \\
\hline ITO & Sol-gel/MOD & Transmitância: 95 \% na região do visível & Eletrodo transparente & 34 \\
\hline Nanorods de ITO & $\begin{array}{l}\text { Evaporação por feixe de } \\
\text { elétrons }\end{array}$ & Transmitância 90 \% na região do visível & Sensor e Biossensor & 35 \\
\hline ITO/V-TiO 2 & RF magnetron sputtering & $\begin{array}{c}\text { Espessura do filme: } 80 \mathrm{~nm} \\
\text { Fotocorrente: } 53 \mu \mathrm{A} \\
\text { Band gap: } 3,9-4,2 \mathrm{eV}\end{array}$ & Fotocatálise & 36 \\
\hline Nanorods de ITO/GaSb & $\begin{array}{l}\text { Deposição por feixe de } \\
\text { elétrons }\end{array}$ & $\begin{array}{c}\text { Índice de refração: } 1,9 \\
\text { Densidade de corrente: } 72,58 \mathrm{~mA} / \mathrm{cm}^{2}\end{array}$ & Células Solares & 37 \\
\hline $\begin{array}{l}\text { Nanodots de ITO/grafeno/In- } \\
\text { GaN }\end{array}$ & MOCVD & $\begin{array}{c}\text { Transmitância } 92 \text { \% na região do visível } \\
\text { Diâmetro de partículas: } 150 \mathrm{~nm}\end{array}$ & Células Solares & 38 \\
\hline Nanopartículas de ITO & Spin coating & $\begin{array}{l}\text { Diâmetro de partículas: } 30-40 \mathrm{~nm} \\
\text { Espessura do filme: } 170 \mathrm{~nm}\end{array}$ & Eletrocatálise & 39 \\
\hline
\end{tabular}

Cristais de ITO

MOCVD

Espessura do filme: $90 \mathrm{~nm}$ Transmitância:

$95 \%$ na região UVA

LEDs

40

Resistência da folha: $100 \Omega / \Upsilon$

Band gap: $4,7 \mathrm{eV}$

Espessura do filme: $50 \mathrm{~nm}$

Resistividade: $0,22 \mathrm{~m} \Omega . \mathrm{cm}$

Filme de Ga-ITO

Co-sputtering

Transmitância $91 \%$ na região do visível

TFT-LCD 
[A]
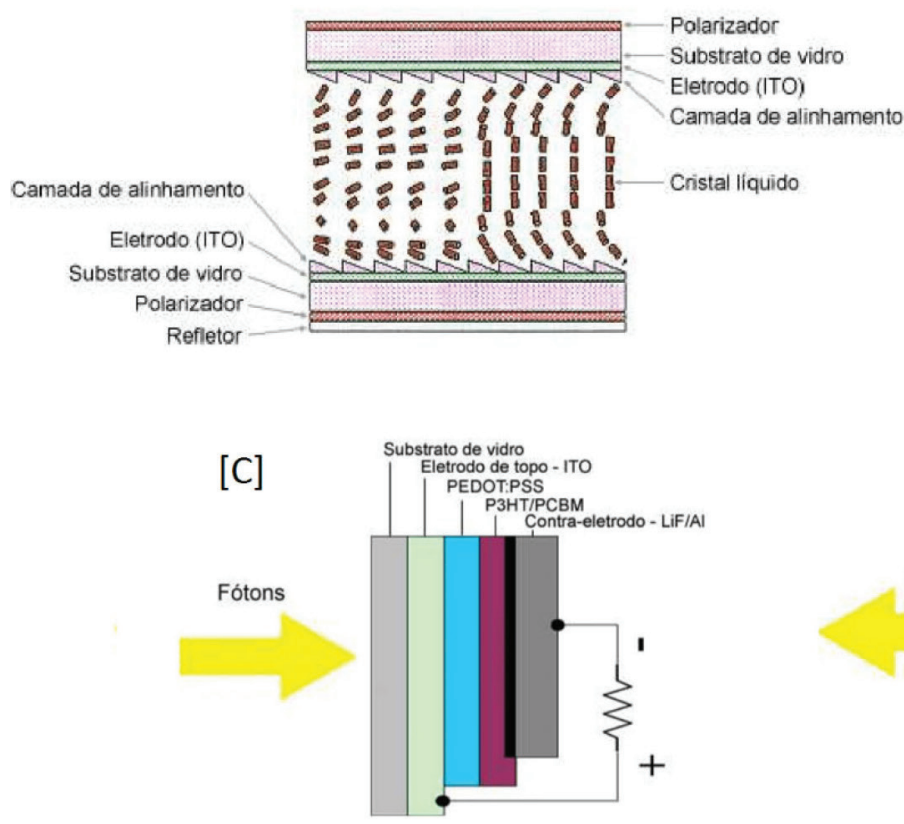

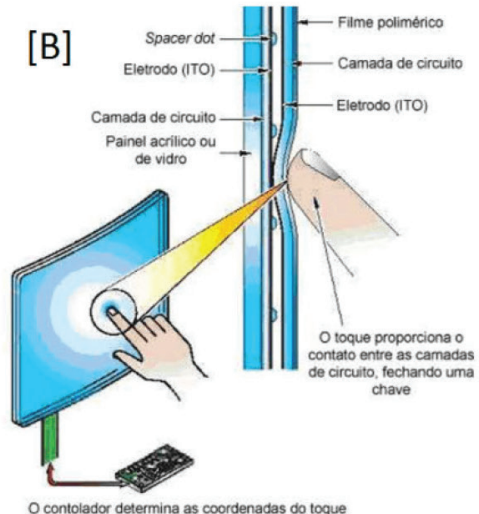

[D]

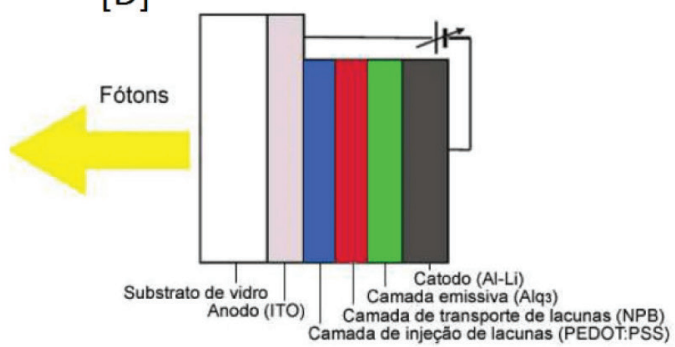

Figura 5. Estruturas típicas de [A] célula de cristal líquido, usada na fabricação de LCD, [B] tela sensível ao toque, [C] célula solar orgânica e [D] OLED resistivo. Adaptada da Ref. 42

Tem sido considerado que nas televisões, os LCDs sejam substituídos por OLEDs gradualmente, pois possuem alta luminescência (acima de $100000 \mathrm{~cd} / \mathrm{m}^{2}$ ), alta eficiência de emissão de luz (mais de $10 \mathrm{~lm} / \mathrm{w})$, tempo de resposta rápido (ms), baixa tensão de condução (corrente contínua) e, finalmente, por consumirem menos energia pelo fato de gerarem luz própria. ${ }^{13,43}$

Os OLEDs têm sido tradicionalmente fabricados em substrato de vidro, no entanto, possuem várias desvantagens para certas aplicações, porque o substrato de vidro é muito frágil, pesado e não flexível. ${ }^{43-45}$ Por isso, os OLEDs flexíveis empregando substratos de polímeros vem despertando um grande interesse. Esses substratos de polímeros, normalmente PET, possuem a capacidade de dobrar ou enrolar a tela em qualquer formato. Isso significa que os OLEDs flexíveis, também podem ser laminados em para-brisas automotivos ou cockpit de aeronaves. Todavia, a baixa estabilidade térmica do substrato de polímero $\left(\mathrm{T}_{\mathrm{g}}=80^{\circ} \mathrm{C}\right)$ dificulta o processo de fabricação com ITO, pois estes materiais requerem temperaturas de processamento superiores a $200{ }^{\circ} \mathrm{C} \cdot \cdot^{13,43-45}$

Em células solares, o ITO pode ser empregado como substrato transparente. ${ }^{46}$ Geralmente é depositado sobre vidro ou polímeros. Em substrato de silício atua como uma camada antirefletora, devido ao seu índice de refração. Dada a sua alta condutividade, melhora a eficiência na coleta da corrente elétrica. ${ }^{46} \mathrm{O}$ desafio tem sido solucionar o conflito entre transparência e o conceito fotônico. Uma vez que, o princípio fotovoltaico é absorver fótons e convertê-los em energia, enquanto transparência significa deixar passar o maior número de fótons possível. Nos últimos cinco anos, vários trabalhos analisaram a utilização do ITO em células solares mostrando que a tecnologia ainda continuará ser comercializada por alguns anos, enquanto novas tecnologias são desenvolvidas. ${ }^{46-50}$

Atualmente, vidros arquitetônicos ou janelas inteligentes (conservadores de energia) têm atraído muita atenção devido ao seu potencial de modular reversivelmente as radiações em resposta às variações nas condições ambientais. Isso ocorre porque o ITO não é transparente à radiação IR e, é usado como revestimento a fim de tornar o aquecimento e arrefecimento dos edifícios mais eficientes em termos energéticos. ${ }^{51}$ Nos óculos de proteção para soldadores, é usado pulverizado funcionando como um revestimento de refusão IR protegendo os olhos contra radiação térmica. ${ }^{51}$ Em lâmpadas de vapor de sódio de baixa pressão é usado como filtro de luz. A radiação infravermelha é refletida de volta para a lâmpada, o que aumenta a temperatura dentro do tubo e melhorando o seu desempenho. ${ }^{13}$

\section{Sensores e Biossensores}

Durante a última década, sensores e biossensores a base de ITO foram descritos na literatura. Suas propriedades elétricas e ópticas o habilitam para serem usados como eletrodos. Possuem uma vida útil longa devido à sua alta estabilidade. Diferentes metodologias de sínteses têm sido utilizadas para a produção dos eletrodos destacando-se a formação de monocamadas auto organizadas (SAMs, Self-Assembled Monolayers), a deposição eletroquímica, a deposição por eletroforese, a adsorção e a polimerização. .,52 $^{8}$

Em trabalho recente, Aydin e Sezgintürk ${ }^{8}$ mostraram as mais atuais e relevantes pesquisas utilizando diferentes estratégias de modificações do eletrodo de ITO. A introdução de nanomateriais como nanopartículas, nanofios, nanotubos de carbono, grafeno e pontos quânticos (Quantum Dots) com diferentes morfologias melhoram muito a sua sensibilidade. Outra vantagem de usar a combinação do ITO com nanomateriais é a sua capacidade de acelerar a eficiência de transferência de elétrons. Esses nanomateriais são usados para melhorar a detecção do analito, aumentar a faixa de detecção (maior especificidade e menor quantidade de analito requerido) e diminuir o limite de detecção. Devido a essas vantagens, se prevê para os biossensores baseados em ITO um grande futuro, sobretudo, em métodos de triagem para monitoramento ambiental, ${ }^{20,52-55}$ controle de alimentos ${ }^{56,57}$ e diagnósticos clínicos. ${ }^{8}$

Em sensores de $\mathrm{pH}$, o ITO pode ser aplicado para detectar íons $\mathrm{H}^{+}{ }^{52}$ Neste caso, a sensibilidade é explicada pela presença de três tipos de sítios na superfície do ITO, ou seja, grupos carregados negativamente ITO', grupos neutros ITOH e grupos com carga positiva $\mathrm{ITOH}^{+}$. Após a mudança de $\mathrm{pH}$ do eletrólito, ocorre uma mudança na concentração de prótons da superfície do ITO, modulando a 
corrente do dispositivo SEGFET (Separative Extended Gate Field Effect Transistor). ${ }^{52}$

Um sensor de amônia baseado no filme fino de ITO em um substrato de quartzo, fabricado por pulverização com RF e tratamento térmico, mostrou bons desempenhos de detecção da $\mathrm{NH}_{3} \cdot{ }^{53}$ Também apresentou alta resposta, resposta rápida e baixos tempos de recuperação na introdução do gás mesmo em altas temperaturas. Esse sensor é superior a outros anteriormente relatados na literatura devido às vantagens da estrutura simples, fácil operação, baixo custo e excelente desempenho.

Pontos quânticos de grafeno (GQDs, Graphene Quantum Dots) foram sintetizados com diâmetro médio de $7 \mathrm{~nm}$ e utilizados na fabricação de um imunosensor eletroquímico para a detecção de uma toxina alimentar, a aflatoxina B1 (AFB1). ${ }^{56} \mathrm{~A}$ técnica de deposição eletroforética foi utilizada para depositar os GQDs quimicamente sintetizados no ITO (substrato de vidro). ${ }^{57}$ Além disso, os anticorpos monoclonais de AFB1 foram covalentemente imobilizados no eletrodo GQDs / ITO usando EDC-NHS como um crosslinker. O imunosensor eletroquímico apresentou alta sensibilidade $213.88 \Omega$ $\left(\mathrm{ng} \mathrm{mL} \mathrm{mL}^{-1} \mathrm{~cm}^{-2}\right.$. O limite de detecção para amostras padrão e amostras de milho contaminado foi quantificado em $0,03 \mathrm{ng} \mathrm{mL}^{-1} \mathrm{e} 0,05 \mathrm{ng} \mathrm{g}^{-1}$, respectivamente. Este resultado indica sua potencial aplicação na detecção de aflatoxina B1 em amostras de alimentos.

Outra utilização do ITO é em diagnósticos clínicos. ${ }^{8}$ A partir de um simples método de preparação, Drop-casting, foi possível obter um imunosensor (ITO/TiO $/$ /EPM/anti-PSA/BSA/PSA). ${ }^{33}$ A epinefrina melanina (EPM) solúvel em água pós-síntese, preparada a partir da auto-polimerização da epinefrina, foi utilizada como revestimento de superfície do $\mathrm{TiO}_{2}$. Esse revestimento de EPM aumentou muito o sinal da fotocorrente, enquanto, a imobilização do anticorpo PSA e o bloqueio adicional de sítios de ligação não específicos usando BSA diminuíram a fotocorrente, isso devido à formação de uma camada de proteína. Esse efeito de impedimento estérico e a ligação específica de moléculas de PSA na superfície diminuíram ainda mais o sinal da fotocorrente. Esse resultado indica a capacidade de reconhecimento biológico do anticorpo PSA, que pode ser facilmente imobilizado, com alta seletividade e estabilidade, mostrando o grande potencial de aplicação como biossensor.

\section{Fotoeletrocatálise}

Nos últimos anos, o ITO vem despertando atenção em eletrocatálise devido às suas propriedades, podendo ser usado como suporte ou como catalisador em heteroestruturas ${ }^{58-61}$ As propriedades de superfície como área superficial, face cristalina e defeitos superficiais facilitam a transferência dos elétrons. Se o material do eletrodo é quimicamente inerte e fracamente adsorvente, ele pode tornar a reação de transferência de elétron mais lenta. As atividades eletrocatalíticas intrínsecas dos ITOs são muito inferiores às da maioria dos metais e eletrodos de carbono, fornecendo uma ampla variação de potencial, bem como baixa e reprodutível corrente de fundo. Por essas razões, o ITO é comumente utilizado como substrato dos eletrocatalisadores em reações de water splitting e oxidação da água. ${ }^{58-60}$ Além disso, os estudos mais promissores utizando o ITO como substrato são na área de imobilização de superfície de cromóforos moleculares. ${ }^{61}$

\section{Semicondutores}

O desenvolvimento de materiais semicondutores, utilizados em diodos, transistores e processadores miniaturizados (chips), provocou uma verdadeira revolução tecnológica na eletrônica, estando presentes em todo e qualquer equipamento computadorizado ou que utiliza ondas de rádio.
Há uma grande variedade de materiais semicondutores de índio. De acordo com a estrutura e a composição química do material, estes semicondutores podem ser utilizados na forma cristalina e amorfa. De acordo com sua composição, podem ser divididos em: (i) compostos binários tais como arseneto de índio (InAs), telureto de índio (InSb) e fosfeto de índio (InP); (ii) compostos ternários, como InGaAs e $\mathrm{CuInSe}_{2}$; (iii) compostos quaternários, como CuInGaSe, InTlAsSb, InAsGaSb. Também podem ser encontrados em heterojunções GaInAs/InP, e como quantum dots do tipo InSb, InGaAs e InAs, em substrato de GaAs. ${ }^{14,62}$

Existem, basicamente, duas metodologias para o crescimento desses materiais. Uma é a convencional, em que é usada mais de um precursor, seja elementar ou molecular; e a segunda que envolve o uso de uma única fonte molecular. Nos processos de Deposição de Vapor Químico de Organometálico (MOCVD, Metalorganic Chemical Deposition), deposição de camada atômica (ALD, Atomic Layer Deposition) ou Epitaxia por Fase de Vapor (MOVPE, Metalorganic Vapor-Phase Epitaxy) são utilizados tanto precursores de fonte única $\left(\left[\mathrm{Me}_{2} \mathrm{InSbtBu}_{2}\right]_{3}\right.$ ) quanto aqueles com mais de uma fonte, como alquilas $\left(\mathrm{Me}_{3} \mathrm{In}\right)$, adutos $\left.\left(\mathrm{Et}_{2} \mathrm{In}_{-} \mathrm{PEt}_{2}\right]\right)$ e hidretos $\left(\mathrm{AsH}_{3}, \mathrm{PH}_{3}\right) .{ }^{14,63}$ Contudo, os precursores de fonte única ainda precisam ser melhorados para alcançar resultados significativos no crescimento desses materiais. As propriedades elétricas e ópticas dos semicondutores sintetizados por todas as técnicas mencionadas são criticamente dependentes da pureza (tanto metálica quanto orgânica) do (s) precursor (es) organometálico (s). Quando ocorrem a incorporação de impurezas na camada superficial dos materiais, temos interferências nas energias de seus band gaps, levando, consequentemente, a importantes alterações nas propriedades semicondutoras, como a diminuição da mobilidade eletrônica, e/ou redução da eficiência de fotoluminescência favorecidos pela presença de efeitos de recombinação não-radiativos. ${ }^{14,63}$

$\mathrm{O}$ InP foi utilizado na fabricação de sintetizadores de frequência rápidos que operam em cerca de sete bilhões de ciclos por segundo. Este resultado é três vezes mais rápido que os primeiros sintetizadores disponíveis. Diodos do tipo Gunn baseados em InP, permitiram um desenvolvimento notável na tecnologia de radares militares e industriais. Estes diodos também têm sido utilizados em dispositivos optoeletrônicos como diodos de laser e transistores de alta temperatura. ${ }^{64}$ Outra aplicação importante do InP é o seu uso como substrato para células solares, como é o caso do arseneto de índio e gálio (InGaAs) ${ }^{65}$

Os semicondutores InAsSb, InTlSb, InSbBi, InTlAsSb e InAsGaSb têm sido utilizados em lasers de infravermelho. ${ }^{14}$ Os nitretos e os fosfetos de índio-gálio ( $\mathrm{InGaN}$ e InGaP) são usados em diodos de laser e diodos emissores de luz (LEDs). ${ }^{14}$ InGaN é usado para emitir a cor azul nos LEDs e o comprimento de onda de emissão varia com a composição. Uma lâmpada LED contém, em média, $29 \mu \mathrm{g}$ de índio. ${ }^{14}$

O índio é ainda utilizado na composição de células fotovoltaicas como seleneto de cobre, índio e gálio ( $\mathrm{CuIn}_{\mathrm{x}} \mathrm{Ga}_{1-\mathrm{x}} \mathrm{Se}_{2}$, CIGS) ${ }^{66}$ também chamado de célula solar de filme fino de segunda geração. Em 2015 essas células solares representaram 2\% da produção global de painéis solares e consumiram cerca de 40 toneladas de índio. $\mathrm{O}$ desenvolvimento dessa tecnologia é um dos exemplos de sucesso da interação entre a comunidade acadêmica e o setor produtivo. Vários desenvolvimentos posteriores foram realizados que levaram a melhorar a eficiência da fotocorrente. ${ }^{14,46,47,66}$ Além do CIGS, outras células têm mostrado resultados promissores de estabilidade e eficiência tais como aquelas baseadas em $\mathrm{CuInSe}_{2}$ (CIS) e heterojunções GaInAs/ InP. $46-47,66-68$

Recentemente, um novo material de índio vem se mostrando altamente promissor. Trata-se do óxido de zinco-índio-gálio amorfo ( $\alpha$-IGZO), que é amplamente utilizado na indústria de transistores, 
graças à sua alta mobilidade eletrônica de saturação $\left(5 \sim 10 \mathrm{~cm}^{2} / \mathrm{Vs}\right)$ e baixa corrente de desligamento $(<1 \mathrm{pA}) .{ }^{69}$

\section{Ligas e soldas}

As ligas de índio possuem um baixo ponto de fusão, e devido a essa propriedade, podem ser encontradas em uma variedade de aplicações, desde fundições até blindagens de radioterapia. ${ }^{70,71}$ As ligas de índio com bismuto, cádmio, chumbo e estanho de baixo ponto de fusão (entre 50 e $100{ }^{\circ} \mathrm{C}$ ) são usadas em fusíveis de segurança, os quais são utilizados em caixas de alarme de incêndio e em sistemas de sprinklers. ${ }^{14}$ As ligas de InGa podem ser utilizadas para transferir calor de elementos ópticos (espelhos, grades e cristais) em linhas de feixe de radiação síncrotron de alta potência. ${ }^{72} \mathrm{~A}$ liga de gálio-índio-estanho (GaInSb), que é líquida à temperatura ambiente, substitui o mercúrio em alguns tipos termômetros. ${ }^{14} \mathrm{O}$ índio é usado nos transistores de junção bipolar pnp com germânio e em soldas para placas de circuitos impressos. ${ }^{14}$ Usos adicionais das ligas com baixo teor de índio incluem moldes de encapsulamento para componentes eletrônicos e moldes de fundição. ${ }^{14}$

Em engenharia nuclear ligas contendo ${ }^{113} \mathrm{In}$ e ${ }^{115} \mathrm{In}$ têm sido usadas para determinar as magnitudes de fluxos de nêutrons. Em reatores nucleares, a liga com composição $85 \%$ prata, $10 \%$ cádmio e 5\% índio é utilizada como haste de controle de reações nucleares, pois estão dispostas no núcleo do reator de maneira a proporcionar um controle adequado da reatividade, uma vez que são eficientes absorvedoras de nêutrons. ${ }^{14}$

\section{Revestimentos para rolamentos e espelhos}

A primeira aplicação em grande escala do índio foi no revestimento de rolamentos em motores de aeronaves de alto desempenho durante a Segunda Guerra Mundial aproveitando-se do seu baixo coeficiente de atrito. Também é usado nos rolamentos de motores dos carros de Fórmula 1, os quais funcionam sem lubrificantes. ${ }^{14}$ Fios de índio são utilizados como selantes de vácuo e condutores térmicos em aplicações de ultra-alto vácuo e criogenia. ${ }^{72}$

Os espelhos podem ser fabricados através da técnica de chapeamento do índio sobre metais ou através de sua adição, em concentrações muito baixas, em diferentes tipos de vidro. Os espelhos contendo índio refletem tanto quanto espelhos de prata, todavia, apresentam uma melhor resistência à corrosão. ${ }^{14}$

\section{Compostos químicos}

O uso do índio em reações orgânicas despertou uma grande atenção da comunidade científica quando Araki e colaboradores introduziram o índio metálico, pela primeira vez, na reação de Barbier em $1988 .{ }^{73}$ Desde então, o uso do índio em reações orgânicas adquiriu um expressivo progresso que reflete o singular potencial de reatividade em numerosas transformações orgânicas. Tal situação é determinada considerando dois aspectos: o primeiro está ligado ao fato de o índio não reagir com o ar ou com a água e exibir uma baixa heterofilicidade. O segundo aspecto refere-se ao fato do índio apresentar um fraco potencial de estabilização $(5,8 \mathrm{eV})$, comparável aos dos metais alcalinos e, portanto, sendo capaz de promover processos redox. As espécies de organoíndio exibem uma menor acidez de Lewis quando comparadas com a dos derivados de organoalumínio. Os sais de índio (III) são sofrem hidrólise moderada o que se constitui num fator de grande interesse para o desenvolvimento de reações catalisadas por ácido de Lewis, incluindo as reações enantiosseletivas. ${ }^{14}$

O índio, nos estados de oxidação, In (0) ou In (I), pode ser utilizado em reações do tipo Barbier, funcionando como agente redutor, para a alilação de compostos carbonílicos em dimetilformamida ou água. Na reação de Reformatsky, é usado para a síntese de hidroxiésteres e seus produtos de desidratação. Os compostos de triorganoíndio, $\mathrm{R}_{3} \mathrm{In}$, podem sofrer reações de acoplamento cruzado com iodetos ou brometos de arila catalisados por paládio ou níquel. Neste caso, o reagente de índio transfere eficientemente todos os três grupos orgânicos ligados ao metal. Os sais de índio (III) têm sido usados para mediar a abertura do anel de éteres cíclicos, aziridinas ou derivados da lactona. A abertura de epóxidos com tricloreto de índio é bastante utilizada, por dar origem aos compostos carbonilados ou clorohidrinas correspondentes. A acilação de álcoois utilizando-se anidrido acético como reagente pode ser catalisada por $\mathrm{In}(\mathrm{OTf})_{3}$ (triflato de índio) sob condições brandas. ${ }^{14}$ Atualmente, o desenvolvimento de compostos de organoíndio vem crescendo para atender a demanda de reagentes precursores, com elevado grau de pureza, para a utilização na fabricação de semicondutores, ligas, e dispositivos ópticos-eletrônicos.

\section{O ÍNDIO NO CONTEXTO BRASILEIRO}

O Brasil possui reservas do elemento químico índio (In) na região central do país, especificamente no Maciço granítico da Mangabeira, pertencente à denominada província estanífera de Goiás (Figura 6). ${ }^{74}$ Nesta região é possível encontrar a maior concentração média deste elemento (acima de $1 \%$ em massa). O índio ocorre em maior abundância associado aos minerais roquesita $\left(\mathrm{CuInS}_{2}\right)$, dzalindita $\left[\mathrm{In}(\mathrm{OH})_{3}\right]$ e yanomamita $\left(\mathrm{InAsO}_{4} \cdot 2 \mathrm{H}_{2} \mathrm{O}\right)$. Este último é encontrado apenas nesta região..$^{74,75}$

O índio é considerado um metal estratégico para o Brasil em função de suas aplicações em alta tecnologia. Considerando o aumento crescente da demanda internacional este metal se coloca dentro de um contexto favorável para a sua exploração econômica. ${ }^{75}$ Sendo assim, o monitoramento detalhado do quanto se importa e exporta (balança comercial) de In é importante para o país. Entretanto, ao nosso conhecimento, as últimas informações disponibilizadas pelo Departamento Nacional de Produção Mineral (DNPM) do Ministério de Minas e Energia ${ }^{76}$ veiculadas no Anuário Mineral do Brasil foram reportadas em 2001, o que demonstra a necessidade de uma atualização das informações. No documento da DNPM os dados econômicos do In referentes à exportação e importação são apresentados conjuntamente com os elementos químicos gálio $(\mathrm{Ga})$, háfnio (Hf), nióbio $(\mathrm{Nb})$ e rênio (Re). No período entre 1998 e 2000 o país importou cerca de $547 \mathrm{t}$ e exportou $1230 \mathrm{t}$ destes elementos equivalente a um valor de US\$ 2.406 e US\$ 31.121 milhões de dólares, respectivamente. ${ }^{76}$ Os Estados Unidos através de um relatório veiculado pelo Laboratório Nacional de Energias Renováveis (NREL), publicado em outubro de 2015 intitulado "The Availability of Indium : The present, Medium Term, and Long Term", apresenta dados econômicos atualizados destacando que a produção de índio, primariamente refinado, entre os anos de 2009 a 2011 , foi de 19 t. ${ }^{77}$

Neste contexto, o desenvolvimento de pesquisas que utilizam o In e seus derivados com foco na ciência, tecnologia e inovação, assim como o desenvolvimento de processos industriais robustos, são importantes para a matriz de desenvolvimento brasileira considerando que nosso país possui reservas potenciais dos minerais associados ao índio. É importante mencionar que a consulta feita nas bases de dados Web of Science e Scopus, utilizando a combinação de palavras "indium and chemical element", para o contexto nacional, resultou em apenas 34 ocorrências nos últimos 20 anos, sendo que a primeira foi relatada em 1998. Esses resultados sugerem fortemente a necessidade de incrementar a pesquisa científica e tecnológica envolvendo o elemento índio para fazer face não só a apropriação do conhecimento, como também sua tradução em ganhos econômicos ligados à sua exploração e aplicação. 


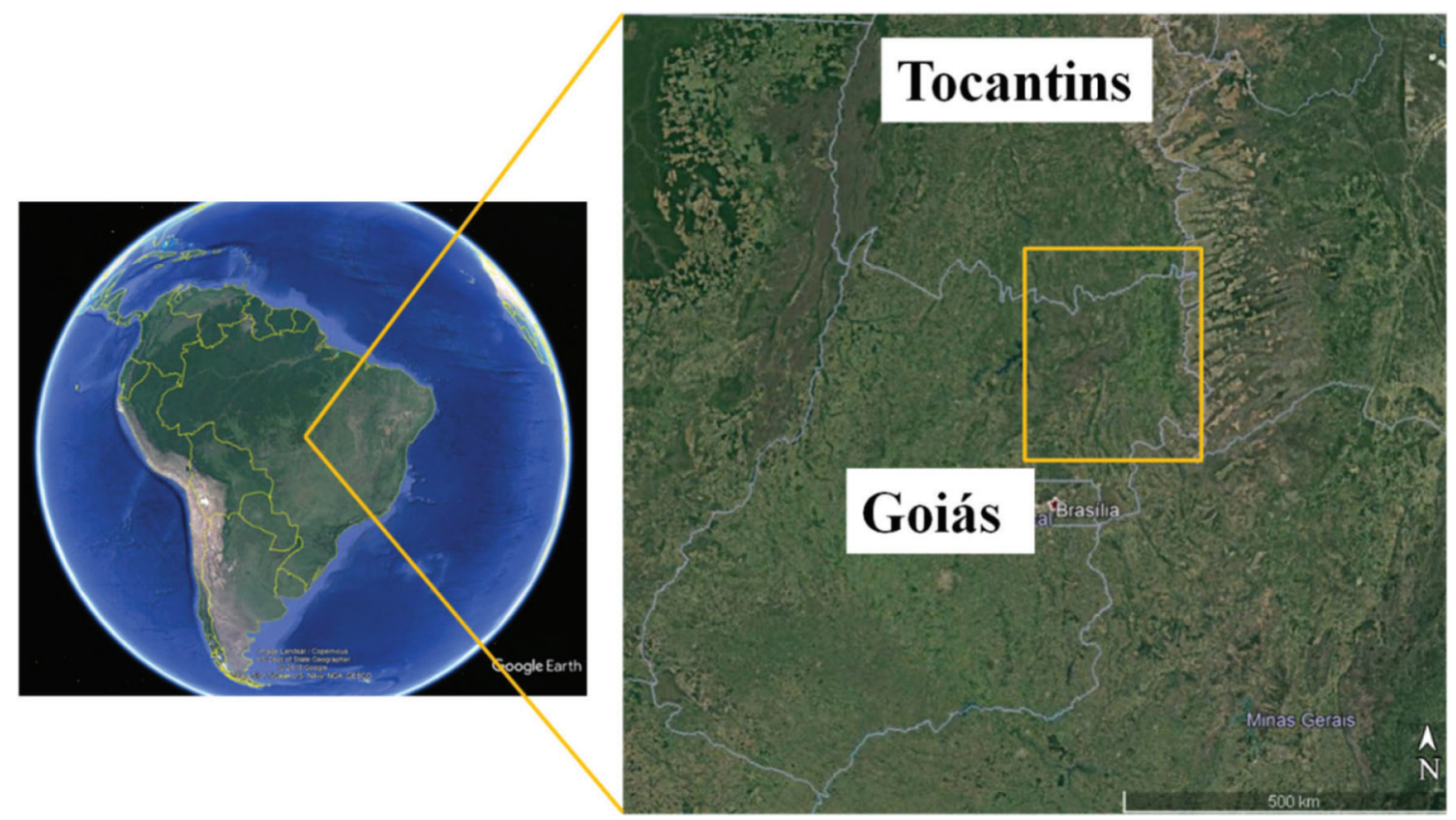

Figura 6. Região em que se localiza o maciço granítico da Mangabeira

\section{CONCLUSÃO}

Neste trabalho, foram avaliados o impacto científico, tecnológico e econômico do índio. As propriedades óptico-eletrônicas do índio e de seus derivados possibilitam sua ampla utilização na fabricação de diversos tipos de dispositivos. Atualmente, existem quatro grandes áreas de aplicações do índio: (i) em filmes finos de óxido de índio-estanho (ITO), (ii) semicondutores, (iii) ligas e soldas, e (iv) compostos químicos. Observou-se uma clara tendência de intensificação das pesquisas em semicondutores, especialmente relacionadas com células fotovoltaicas em diferentes aplicações, o que pode ser um indicativo de que os investimentos futuros, governamentais e privados, poderão ser privilegiados nas próximas décadas. Este movimento está em sinergia com as nanotecnologias, uma vez que, podem ser obtidos novos dispositivos com elevada performance a partir da combinação eficiente de diferentes nanomateriais a base de índio.

Os dados existentes sobre as reservas de mineriais associados ao índio certamente merecem uma abordagem mais aprofundada e precisa, especialmente no que diz respeito à prospecção e definição dos recursos disponíveis para o status atual e garantir meios de suprimento para desenvolvimentos futuros, sobretudo da indústria óptico-eletrônica de ponta.

Outro aspecto importante e oportuno está relacionado com a sustentabilidade, uma vez que o índio e outros elementos utilizados no setor produtivo podem ser "garimpados" do lixo eletrônico. Por se tratar de um problema ambiental emergente, faz-se necessário, o desenvolvimento de processos de reciclagem adequados e eficientes.

O exemplo do metal índio no contexto brasileiro revela a necessidade premente da formatação de programas específicos que contemplem estudos abragentes dos elementos situados à direita da Tabela Periódica, gerando conhecimento autóctone que nos permita participar do desenvolvimento científico e tecnológico em temas de fronteira da ciência mundial.

\section{AGRADECIMENTOS}

Os autores agradecem ao INCT/INOMAT financiado Fapesp, CNPq e CAPES.

\section{REFERÊNCIAS}

1. Enghag, P.; Encyclopedia of the Elements, $1^{\text {st }}$ ed., Wiley-VCH: Weinheim, 2004

2. Schwarz-Schampera, U.; Herzig, P. M.; Indium: Geology, Mineralogy, and Economics, $1^{\text {st }}$ ed., Springer: Heidelberg, 2002.

3. Werner, T. T.; Gavin M. M.; Simon M. J.; Ore Geol. Rev. 2017, 86, 939.

4. Busev, A. I.; International Series of Monographs on Analytical Chemistry: The Analytical Chemistry of Indium; $1^{\text {st }}$ ed., Pergamon Press: Oxford, 1962.

5. Krebs, Robert E. The History and Use of Our Earth's Chemical Elements: A Reference Guide, $2^{\text {nd }}$ ed., Greenwood Press: Connecticut, 2006.

6. Werner, T. T.; Mudd, G. M.; Jowitt, S. M.; Appl. Earth Sci. 2015, 124, 213.

7. Alfantazi, A. M.; Moskalyk, R. R.; Miner. Eng. 2003, 16, 687.

8. Aydin E. B.; Sezgintürk M. K.; Trends Anal. Chem. 2017, 97, 309.

9. U.S. Geological Survey. Mineral Commodity Summaries, 2017, doi. org/10.3133/70180197.

10. Rudnick, R.L. Gao, S. Em Treatise on Geochemistry, $2^{\text {nd }}$ ed.; Turekian, H. D., Holland, K.K., eds.; Elsevier: Oxford, 2014, cap. 1.

11. Duan, H.; Wang, J.; Liu, L.; Huang, Q.; Li, J.; Prog. Photovoltaics Res. Appl. 2015, 24, 83.

12. http://www.prweb.com/releases/2014/08/prweb12120548.htm, acessada em novembro 2019.

13. Ginley, D.; Perkins, J. D.; Robertson, J.; Falabretti, B.; Em Handbook of Transparent Condutors, $1^{\text {st }}$ ed.; Ginley, D., Hosono, H., Paine, D. C., eds.; Springer: New York, 2011, cap.1-2.

14. Malik M. A., O'Brien, P. Em The Group 13 Metals Aluminium, Gallium, Indium and Thallium: Chemical Patterns and Peculiarities; Aldridge, S., Downs, A. J., eds.; John Wiley \& Sons, Ltd.: Chichester, 2011, cap. 10.

15. Babu, P.M.; B. Radhakhrishna; G. Venkata; J. Optoelectron. Adv. Mater. 2004, 6, 205.

16. Schmidt, H.; Flügge, H.; Winkler, T.; Bülow, T.; Riedl, T.; Kowalsky, W.; Appl. Phys. Lett. 2009, 94, 243302.

17. Sawada, M.; Higuchi, M.; Kondo, S.; Saka, H.; J. Appl. Phys. 2001, 40, 3332.

18. Kima, H.; Gilmore, C. M.; J. Appl. Phys. 1999, 86, 6451.

19. Lampert, C. M.; Sol. Energy Mater. 1981, 6, 1. 
20. Afshar, M.; Preib, E. M.; Sauerwald, T.; Rodner, M.; Feili, D.; Straub, M.; König, K.; Schütze, A.; Seidel, H. Sens. Actuators, B 2015, 215, 525 .

21. Han, P.; Xu, S.; Feng, S.; Hao, Y.; Wang, J.; Talanta 2016, 151, 114.

22. Betz, U.; Olsson; M. K., Marthy, J.; Escolá, M. F.; Atamny, F.; Surf. Coat. Technol. 2006, 200, 5751.

23. Zhang, M.; Nakayama, Y.; Pan, L.; Jpn. J. Appl. Phys. 2000, 39, L1242.

24. Kumar, R.; Sudarshan, T. S.; Mater. Technol. 1995, 10, 202.

25. Cao, G.; J. Phys. Chem. B 2004, 108, 19921.

26. Kovtyukhova, N. I.; Mallouk, T. E.; Nanoscale 2011, 3, 1541.

27. Ederth, J.; Heszler, P.; Hultaker, A.; Niklasson, G. A.; Granqvist, C. G.; Thin Solid Films 2003, 445, 199.

28. Neri, G.; Bonavita, A.; Micali, G.; Rizzo, G.; Pinna, N.; Niederberger,M.; Ba, J.; Sens. Actuators, B 2008, 130, 222.

29. Seiki, S.; Wakana, M.; Kasahara Y.; Seki, Y.; Kondo, T.; Wang, M.; Uchida, T.; Haga, K.; Sawada, Y.; Jpn. J. Appl. Phys. 2007, 46, 6837.

30. Vieira, N. C. S.; Ramos, F. E. G.; Queiroz, A. A. A.; Guimarães, F. E. G.; Zucolotto, V.; Mater. Res. 2013, 16, 1156.

31. Lue, C.E.; Wang I. S.; Huang, C. H.; Shiao, Y.T.; Wang, H. C.; Yang, C. M.; Microelectron. Reliab. 2012, 52, 1651.

32. Christodoulou, C.; Wolter, B.; Ioakeimidis, A.; Chouliaras, G.; Wiesner, S.; Lauermann, I.; Centeno, A.; Zurutuza, A.; Fostiropoulos, K.; Thin Solid Films 2019, 682, 57.

33. Ma, H.; Fan, Q.; Fan, B.; Zhang, Y.; Fan, D.; Wu, D.; Wei, Q.; Langmuir 2018, 34, 7744.

34. Alves, O. L.; Ronconi, C. M.; Quim. Nova 2002, 25, 69.

35. Shen, Y.; Lou, Y.; Wang, Z.; Xu, Z.; Coatings 2017, 7, 212.

36. Dholam, R.; Patel, N.; Santini, A.; Miotello, A.; Intern. J. Hydrogen Energy 2010, 35, 9581.

37. Lee, H. Y.; Huang, H. L.; Pchelyakov, O. P.; Pakhanov, N. A.; Prog. Photovolt. Res. Appl. 2016, 24, 195.

38. Seo, T. H.; Shim, J-P.; Chae, S. J.; Shin, G. U.; Kim, B. K.; Lee, D-S.; Lee, Y. H.; Suh, E-K.; Appl. Phys. Lett. 2013, 102, 31116.

39. Seo, M.; Bae, J. H.; Hwang, D. W.; Kwak, B.; Yun, J.; Lim, S. Y.; Chung, T. D.; Electrochim. Acta 2017, 258, 90.

40. Chen, Z.; Zhuo, Y.; Tu, W.; Ma, X.; Pei, Y.; Wang, C.; Wang, G.; Appl. Phys. Lett. 2017, 110, 242101.

41. Choi, J. H.; Kang, S. H.; Oh, H. S.; Yu, T. H.; Sohn, I. S.; Thin Solid Films 2013, 527, 141

42. Damiani, L. R.; Dissertação de Mestrado, Universidade de São Paulo, Brasil, 2010

43. Tak, Y.-H.; Kim, K.-B.; Park, H.-G.; Lee, K.-H.; Lee, J.-R.; Thin Solid Films 2002, 411, 12.

44. Emons, T. T.; Li, J.; Nazar, L. F.; J. Am. Chem. Soc. 2002, 124, 8516.

45. Sohn, S.; Han, Y. S.; Em Organic Light Emitting Diode-Material, Process and Devices, $1^{\text {st }}$ ed.; Ko, S. H., ed.; Intech: Rejika, 2011, pp. 233-274.

46. Husaina, A. A. F.; Hasana, W. Z. W.; Shafiea, S.; Hamidonb, M. N.; Pandey, S. S.; Renewable Sustainable Energy Rev. 2018, 94, 779.

47. Nayak, P. K.; Mahesh, H. J.; Snaith, H. J.; Cahen, D.; Nat. Rev. Mater. 2019, 4, 269.

48. Schmidt, H.; Flügge, H.; Winkler, T.; Bülow, T.; Riedl, T.; Kowalsky, W.; Appl. Phys. Lett. 2009, 94, 243302.

49. Zhou, Y.; Shim, J. W.; Fuentes-Hernandez, C.; Sharma, A; Knauer, K. A.; Giordano, A. J.; Marderb, S. R.; Kippelen, B.; Phys. Chem. 2012, 14,12014 .
50. Hoon Seo, T.; Shim, J.-P.; Jin Chae, S.; Shin, G.; Kyoung Kim, B.; Lee, D.-S.; Hee Lee, Y.; Suh, E.-K.; Appl. Phys. Lett. 2013, 102, 31116.

51. Onodera, R.; Seki, Y.; Seki, S.; Yamada, K.; Sawada, V.; Uchida, T.; Appl. Phys. Express 2013, 6, 26503.

52. Comini, E.; Baratto, C.; Concina, I., Faglia, G.; Falasconi, M.; Ferroni, M.; Galstyan, V.; Gobbi, E.; Ponzoni, A.; Vomiero, A.; Zappa, D.; Sberveglieri, V.; Sberveglieri, G.; Sens. Actuators, B 2013, 179, 3.

53. Lin, C.-W.; Chen, H.-I.; Chen, T.-Y.; Huang, C.-C.; Hsu, C.-S.; Liu, R.-C.; Liu, W.-C.; Sens. Actuators, B 2011, 160, 1481.

54. Choo, T. F.; Saidin, N. U.; Kok, K. Y.; Chem. Phys. Lett. 2018, 713, 180.

55. Lin, Y.; Peng, Y.; Di, J.; Sens. Actuators, B 2015, 220, 1086.

56. Bhardwaj, H.; Singh, C.; Kotnala, R.; Sumana, G.; Anal. Bioanal. Chem. 2018, 410, 7313.

57. Liana, A. E.; Marquis, C. P.; Gunawan, C.; Gooding, J.; Amal, R.; J. Colloid and Interface Sci. 2018, 514, 227.

58. Puthiyapura, V. K.; Pasupathi, S.; Su, S.; Pollet, X. L. B.; Scott, K.; Int. J. Hydrogen Energy 2014, 39, 1905.

59. Hung, C.-H.; Kao, C.-L.; Wu, K.-R.; Electrochim. Acta 2012, 86, 3.

60. Sheehan, S. W.; Thomsen, J. M.; Hintermair, U.; Crabtree, R. H.; Brudvig, G. W.; Schmuttenmaer, C. A.; Nat. Commun. 2015, 11, 6469.

61. Chen, X.; Luais, E.; Darwish, N.; Ciampi S.; Thordarson P.; Gooding J. J.; Langmuir 2012, 28, 9487.

62. Trindade,T.; O'Brien, P.; Pickett, N. L.; Chem. Mater. 2001, 13, 3843.

63. Chen, D.; Ravindra, N. M.; Em Semiconductors: Synthesis, Properties and Applications; Pech-Canul, M. I., Ravindra, N. M., eds.; Springer Nature: Switzerland, 2019, cap. 8.

64. Massidda, S.; Continenza, A.; Freeman, A. J.; de Pascale, T. M.; Meloni, F.; Serra, M.; Phys. Rev. B 1990, 41, 12079.

65. Zhao, H.; Pinna, S.; Sang, F.; Song, B.; Tommaso, S.; Brunelli, S.; Coldren, L. A.; Klamkin, J.; IEEE J. Sel. Top. Quantum Electron. 2019, 25, 4500409 .

66. Choubey, P.C.; Oudhia, A.; Dewangan, R.; Recent Res. Sci. Technol. 2012, 4, 99 .

67. Soydan, A. M.; Yilmaz, P.; Tunaboylu, B.; J. Chem. 2018, ID 5187960.

68. Laube, G.; Kohler, U.; Weidlein, J.; Scholz, F.; Streubel, K; Dieter, R. J.; Karl, N.; Gerdon, M.; J. Cryst. Growth 1988, 93, 45.

69. Chung, J.-M.; Wu, F.; Jeong, S.-W.; Kim, J.-H.; Xiang, Y.; Nanoscale Res. Lett. 2019, 14, 165.

70. Weissler, G. L.; Vacuum physics and technology; Academic Press: San Diego, 1990, p. 296.

71. Surmann, P.; Zeyat, H.; Anal. Bioanal. Chem. 2005, 383, 1009.

72. Hulbert, S. L.; Rev. Sci. Instrum. 1992, 63, 505.

73. Araki, S.; Ito, H.; Butsugan, Y.; Synth. Commun. 1988, 18, 453; Araki, S.; Ito, H.; Butsugan, Y.; J. Org. Chem. 1988, 53, 1831.

74. Moura, M. A.; Botelho, N. F.; Olivo, G. R.; Kyser, K.; Pontes, R. M.; Ore Geol. Rev. 2014, 60, 36.

75. Moura, M. A.; Botelho, N. F.; Mendonça, C.; The Canadian Mineralogist 2007, 45, 485.

76. http://www.anm.gov.br/dnpm/publicacoes/serie-estatisticas-e-economiamineral/anuario-mineral/anuario-mineral-brasileiro, acessada em novembro 2019.

77. Lokanc, M.; Eggert, R.; Redlinger, M.; The availability of indium: the present, medium term and long term, NREL, October 2015. 